\title{
LIBERDADE DE CÁTEDRA VERSUS PRÍNCÍPIO DA PREVALÊNCIA DOS INTERESSES DA CRIANÇA E DO ADOLESCENTE
}

\author{
FREEDOM OF CHAIR VERSUS PRINCIPLE OF PREVALENCE OF CHILD AND \\ ADOLESCENT INTERESTS
}

\author{
Enoque Feitosa Sobreira Filho ${ }^{1}$ \\ Sandra Mara Maciel de Lima² \\ Orides Mezzaroba ${ }^{3}$ \\ Frederico Slomp Neto ${ }^{4}$
}

\begin{abstract}
RESUMO
O presente artigo tem como objetivo identificar os limites da liberdade de cátedra prevista na Constituição Federal de 1998 em possível colisão com o Princípio da Prevalência da Criança e do Adolescente. Por meio de pesquisa bibliográfica, constata-se a possível coexistência entre a liberdade de cátedra e o Princípio da Prevalência da Criança e do Adolescente, levando em consideração que o direito dos discentes deve prevalecer, sem que o direito dos docentes sejam limitados. Conclui-se que há limites para a cátedra de docente que leciona para adolescente, que se encontra no Princípio da Prevalência dos Interesses da Criança e do Adolescente. Logo, o adolescente deve de ter acesso ao conhecimento previsto para sua idade e série, sem sofrer doutrinações políticas e ideológicas, frutos de convicções pessoais do docente.
\end{abstract}

Palavras-chave: Liberdade; Cátedra; Adolescente; Limites.

\footnotetext{
${ }^{1}$ Coordenador Nacional do GT "Ética e Cidadania" da Associação Nacional de Pós-Graduação em Filosofia, com mandato até 2020. Fez Graduação em Direito na UFPE. Mestrado em Direito pela mesma instituição. É Doutor em Direito pela UFPE e Doutor em Filosofia pela UFPB. Possui estágio Pós-doutoral em Filosofia do direito pela UFSC. Professor Associado na UFPB, lecionando na Graduação e Pós-Graduação em Direito e em Filosofia. Advogado (licenciado). Professor-visitante da Universidade Eduardo Mondlane (Moçambique).

${ }^{2}$ Doutora em Sociologia pela Universidade Federal do Paraná (2009). Mestra em Administração pela Universidade Federal do Paraná (2002). Graduada em Ciências Econômicas pela Universidade Federal do Paraná (1993). Coordenadora de Tutoria do Curso de Especialização em Gestão de Organizações Públicas -UFPR/UAB (2012/2014). Líder do Grupo de Pesquisa Observatório sobre Direito à Saúde e Cidadania (CNPq/UNICURITIBA) e Membro do Grupo de Pesquisa em Sociologia da Saúde (CNPq/UFPR). Professora do Programa de PósGraduação em Direito Empresarial e Cidadania do UNICURITIBA. Fez estágio Pós-Doutoral na Universidade Federal do Paraná (2015/2016). Tem experiência em: Direito à Saúde. Sociologia da Saúde. Subjetividade. Tecnologias Médicas. Políticas Públicas e Metodologia Científica.

${ }^{3}$ Professor Titular em Dedicação Exclusiva nos Programas de Graduação e Pós-Graduação em Direito (Mestrado e Doutorado) da Universidade Federal de Santa Catarina. Coordenador do Mestrado Profissional em Direito da Universidade Federal de Santa Catarina. Possui Graduação em Direito pela Pontifícia Universidade Católica do Paraná (1986). Especialização em Filosofia da Educação pela Pontifícia Universidade Católica do Paraná (1989). Mestrado em Direito pela Universidade Federal de Santa Catarina (1991). Doutorado em Direito pela Universidade Federal de Santa Catarina (2000). Pós- Doutorado junto à Universidade de Coimbra - Portugal (2008).

${ }^{4}$ Mestrando em Direito Programa de Pós-Graduação em Direito Empresarial e Cidadania do Centro Universitário Curitiba - UNICURITIBA, Especialista em Direito Civil e Processo Civil pela Universidade Castelo Branco. Advogado.
} 


\begin{abstract}
This article aims to identify the limits of the freedom of professions provided for in the Federal Constitution of 1998 in a possible collision with the Principle of Child and Adolescent Prevalence. Through bibliographic research, it is possible to verify the possible coexistence between the freedom of professorship and the Principle of Child and Adolescent Prevalence, taking into account that the right of students should prevail, without the right of teachers being limited. It is concluded that there are limits to the professorship of teacher who teaches for adolescents, which is found in the Principle of the Prevalence of the Interests of Children and Adolescents. Therefore, adolescents must have access to the knowledge provided for their age and grade, without suffering political and ideological indoctrinations, the fruit of the teacher's personal convictions.
\end{abstract}

Keywords: Freedom; Chair; Teenager; Limits. 


\section{INTRODUÇÃO}

O objetivo deste artigo é identificar os limites da liberdade de cátedra prevista na Constituição Federal de 1998 em possível colisão com o Princípio da Prevalência da Criança e do Adolescente. Os dados foram coletados por meio de pesquisa bibliográfica.

Atualmente muito se discute, em especial através do Movimento Escola Sem Partido, se há limites para a liberdade de cátedra para docentes que lecionam para crianças e adolescentes.

Pois, se de um lado, o docente tem assegurado constitucionalmente o direito de livre ensinar, pesquisar e divulgar o conhecimento, de outro, os menores têm o direito de lhes ser aplicado a prevalência absoluta de seus interesses.

A questão se encontra na coexistência e no, aparentemente, conflito existente entre dois direitos que tem como fonte a própria Constituição Federal. Analisando sobre qual deve prevalecer, na impossibilidade de ambos poderem ser plenamente observados simultaneamente.

Na primeira parte deste artigo, discute-se a liberdade de cátedra no Brasil; na segunda parte, apresenta-se o princípio da prevalência dos interesses da criança e do adolescente; na terça parte, confronta-se o direito de ensinar livremente e a prevalecia dos interesses da criança e do adolescente. Por fim, apresenta-se as considerações finais.

\section{LIBERDADE DE CÁTEDRA NO BRASIL}

Cátedra é uma expressão que deriva do latim e significa cadeira, púlpito ou tribuna de onde se faz prelações ou se ensina, tendo suas raízes em assento litúrgico de destaque na igreja (MICHAELIS, 2020).

Na Constituição Federal de 1988, especificamente no Art. 206, II, foi assegurada a: "liberdade de aprender, ensinar, pesquisa e divulgar o pensamento a arte o saber" (BRASIL, 1988).

Por sair de um período ditatorial (1964-1985), quando as garantias e direitos individuais estavam extremamente mitigados, o constituinte originário inseriu no texto constitucional níveis elevados de liberdades (TELLES JUNIOR, 2016).

Sobre a questão da liberdade do docente em sala de aula, Abrão manifesta-se:

Para que o professor possa ensinar é necessário ter liberdade de pensamento, para desenvolver modelos pedagógicos os quais se adaptem às necessidades de seus alunos, ou, até mesmo, ter liberdade para reconhecer que muitas vezes ensinar é levar 
o aluno a aprender por si só, como é o caso do professor orientador, ou maiêutico, para relembrarmos Sócrates. (ABRÃO, 2016, p. 1083)

Sendo assim, deve haver liberdade para que o docente possa desenvolver os processos pedagógicos que se ajustem à necessidade dos discentes, levando em consideração, as mais diversas variáveis, tais como idade, local de moradia, classe social etc.

Ademais, analisando a questão da liberdade do docente em sala de aula, a Ministra Carmem Lúcia se manifestou da seguinte forma na análise da Arguição de Descumprimento de Preceito Fundamental ${ }^{\circ} 548$, in verbis:

\begin{abstract}
Liberdade de pensamento não é concessão do Estado. É direito fundamental do indivíduo que a pode até mesmo contrapor ao Estado. Por isso não pode ser impedida, sob pena de substituir-se o indivíduo pelo ente estatal, o que se sabe bem onde vai dar. E onde vai dar não é o caminho do direito democrático, mas da ausência de direito e déficit democrático Portanto, qualquer tentativa de cerceamento da liberdade do professor em sala de aula para expor, divulgar e ensinar é inconstitucional. ( ..) Também o pluralismo de ideias está na base da autonomia universitária como extensão do princípio fundante da democracia brasileira, que é exposta no inc. V do art. 1o. da Constituição do Brasil. (BRASIL, 2018, grifos nossos)
\end{abstract}

Já no Art. 206, inciso III da Constituição foi assegurado "o pluralismo de ideias e de concepções pedagógicas, e coexistência de instituição públicas e privadas de ensino" (BRASIL, 1988) com a finalidade de evitar, principalmente, duas situações: o engessamento das técnicas pedagógicas e o monopólio da educação pelo ente estatal.

Engessar as técnicas pedagógicas pode inviabilizar qualquer forma de inovação na educação.

Existem inúmeras técnicas pedagógicas, cada uma com seus pontos fortes e fracos. Podemos citar: as pedagogias críticas (Paulo Freire, Habermas etc.), pedagogias livres não diretivas (Rousseau, Tolstoi etc.), pedagogias da inclusão e da cooperação, pedagogia lenta e sustentável, pedagogia sistêmica (multidimensionalidade, inteligência transgeracional e família como primeiro plano), pedagogias do conhecimento integrado (através de perguntas, questionamentos e hipóteses), pedagogias das diversas competências (focada nas habilidades), e muitas outras com podem não estar nesta classificação. (CARBONELL, 2016). Se fosse privilegiada uma única concepção pedagógica toda esta área de exploração do conhecimento seria extinta.

Para Rodrigues e Marocco, a liberdade de cátedra relaciona-se ao tipo de aula, tais como recursos e obras utilizadas, conforme segue: 
[...] além das escolhas mais propriamente ligadas à didática - tipo de aula e de atividades, recursos tecnológicos, etc. -, está também incluída a liberdade de escolha de textos e obras, desde que contenham o conteúdo a ser ministrado e, no seu conjunto, permitam o acesso ao pluralismo de ideias presente no campo específico do conhecimento, e que não contenham material que endosse preconceitos e discriminações. (RODRIGUES \& MAROCCO, 2014, p. 9)

O monopólio da educação pelo ente estatal, por sua vez não deixaria opção aos cidadãos, limitando com isso as próprias liberdades individuais.

Para Tavares, o Estado cumpre e respeita o direito a educação quando deixar de ser "dono do conhecimento", in verbis:

Nesse sentido, o Estado cumpre e respeita o direito à educação quando deixa de intervir de maneira imperial ditando orientações específicas sobre a educação, como "versões oficiais da História" impostas como únicas admissíveis e verdadeiras, ou com orientações políticas, econômicas ou filosóficas. Também cumpre a referida dimensão deste direito quando admite a pluralidade de conteúdos (não veta determinadas obras ou autores, por questões ideológicas, políticas ou morais). (TAVARES, 2018, p. 773)

Pelo que se constata, tanto na própria Constituição Federal, quanto da análise pelo interprete, que a liberdade para ensinar é ampla, seja quanto à técnica utilizada, ou sobre o conteúdo ministrado.

No Brasil vem prevalecendo a liberdade acadêmica no sentido da tradição norteamericana, também designada como "for the common good school", em que se reconhece uma relação entre a liberdade acadêmica e a democracia. Para Travincas:

Entre as vertentes que anuem quanto à relevância jurídica da liberdade acadêmica situa-se a assim designada "for the common good" school, cuja elaboração é especialmente devota à tradição norte-americana. Ela acorda quanto à existência de uma relação bidirecional entre liberdade acadêmica e democracia - aquela se realiza nessa; essa depende daquela para ser efetivada -, daí o porquê de a tutela da liberdade acadêmica se dar para e, ao mesmo tempo, nos termos exigidos pelo princípio democrático (TRAVINCAS, 2016, p. 44)

A liberdade de ensinar encontra relação direta com direitos fundamentais, tais como manifestação do pensamento, liberdade de expressão da atividade intelectual, científica e de comunicação, independente de censura ou licença e a liberdade de profissão. Neste sentido, escreve Travincas: 
No artigo $5^{\circ}$ da Constituição de 1988 encontra-se um conjunto de direitos fundamentais que forma com a liberdade de ensinar uma rede de relações. Dele pertencem a liberdade de manifestação do pensamento (inciso IV), a liberdade de expressão da atividade intelectual, científica e de comunicação, independente de censura ou licença (inciso IX) e a liberdade de profissão (inciso XIII). (TRAVINCAS, 2016, p. 117)

Portanto, o texto da Constituição Federal de 1988 protege a liberdade enquanto direito geral logo no caput do Art. $5^{\circ}$, assegurando estas sob diferentes aspectos (BRASIL, 1988).

\section{PRINCÍPIO DA PREVALÊNCIA DOS INTERESSES DA CRIANÇA E DO ADOLESCENTE}

Os interesses da criança e do adolescente, no que diz respeito à vida, à saúde, à alimentação, ao lazer, à profissionalização, à cultura, à dignidade, à liberdade, à convivência familiar e comunitária e à educação, foram tratados com prioridade absoluta no texto constitucional, o qual possui a seguinte redação:

Art. 227. É dever da família, da sociedade e do Estado assegurar à criança, ao adolescente e ao jovem, com absoluta prioridade, o direito à vida, à saúde, à alimentação, à educação, ao lazer, à profissionalização, à cultura, à dignidade, ao respeito, à liberdade e à convivência familiar e comunitária, além de colocá-los a salvo de toda forma de negligência, discriminação, exploração, violência, crueldade e opressão. (BRASIL, 1988, grifos nossos)

Seguindo a lógica do texto Constitucional o Estado da Criança e do Adolescente estabeleceu o Princípio da Prevalência dos Interesses da Criança e do Adolescente. O qual se exterioriza de forma explicita na redação do Art. $6^{\circ}$ do referido estatuto:

Art. $6^{\circ} \mathrm{Na}$ interpretação desta Lei levar-se-ão em conta os fins sociais a que ela se dirige, as exigências do bem comum, os direitos e deveres individuais e coletivos, e a condição peculiar da criança e do adolescente como pessoas em desenvolvimento. (BRASIL, 1990)

Para Elias, as crianças e os adolescentes são sujeitos especiais de direito, sendo os seus direitos prioritários, inclusive, quanto aos direitos de seus pais, tutores ou guardiões:

Há de se ter em consideração que a criança e o adolescente são sujeitos especiais de direito e, destarte, todas as decisões devem direcionar-se à sua proteção integral. Os direitos dos pais, do tutor ou do guardião devem vir em segundo lugar. Enfim, devese observar o melhor interesse do menor, em cada ocasião, embora não se deva julgar contra legem. (ELIAS, 2010, p. 18) 
O Estatuto da Criança e do Adolescente estabelece, com autorização Constitucional, uma forma especial de se interpretar o direito, todas as vezes que o titular do direito seja uma criança ou um adolescente. Atentos para esta situação Rossato, Lépore e Cunha, afirmam que devem ser observados os seguintes critérios especiais de interpretação:

\begin{abstract}
Apesar de claramente inspirado no art. $5^{\circ}$ da Lei de Introdução às Normas de Direito Brasileiro (LINDB), o Estatuto determina, em dispositivo próprio (art. $6^{\circ}$ ), que suas normas devem ser interpretadas considerando-se alguns critérios especiais, que são: a) os fins sociais a que ele se dirige; b) as exigências do bem comum; c) os direitos e deveres individuais e coletivos; e d) a condição peculiar da criança e do adolescente como pessoas em desenvolvimento (ROSSATO, LÉPORE \& CUNHA, 2017. p. 8596)
\end{abstract}

Logo, neste entendimento devem ser observados também, os fins sociais a que eles se dirigem, as exigências do bem comum, os direitos individuais e, por fim, a condição peculiar da criança e do adolescente como pessoas em desenvolvimento.

Sempre o aplicador da lei deve observar em suas decisões as condições peculiares das crianças e dos adolescente, um vez que não estão com a formação intelectual completa. Neste sentido, se manifesta Araújo Jr. in verbis:

Do texto da norma, merece destaque a parte final, que claramente constitui o "princípio geral" que deve orientar o aplicador do direito, no sentido de que este sempre considere, quando de suas decisões, "a condição peculiar da criança e do adolescente como pessoas em desenvolvimento”. (ARAÚJO JÚNIOR, 2019, p.6)

Os adolescentes ainda estão em processo formação, adotando comportamento de risco e de experimentação, os quais podem lhes perseguir por toda a vida, sendo um dos motivos, que justificam uma interpretação legal onde prevaleçam seus interesses. Neste sentido, é a explanação de Santrock (2014, p. 91): "Muitos comportamentos ligados a maus hábitos de saúde e morte prematura em adultos começam durante a adolescência".

Por não estarem com o cérebro totalmente formado, os adolescentes não tem plena capacidade de dominar suas emoções. Conforme, SANTROCK:

[...] embora os adolescentes sejam capazes de emoções muito fortes, seu córtex préfrontal não se desenvolveu adequadamente até o ponto em que eles consigam controlar essas paixões. É como se o córtex pré-frontal ainda não tivesse o freio necessário para reduzir a intensidade emocional da amígdala. (SANTROCK, 2014, p.115) 
Maas e Canabarro afirmam que "a adolescência é reconhecidamente uma fase do desenvolvimento humano de desconstrução e reconstrução de sua própria identidade, da visão de mundo, das relações sociais e familiares" (MAAS \& CANABARRO, 2014, s/p).

Santrock (2014) trata do self como todas as características de uma pessoa, estando relacionada ao autoconhecimento. Com relação a isso, o jovem ainda está encontrando seu lugar no mundo, tentando saber quem é.

Exemplificando a matéria, com relação a forma como os adolescentes se veem, Santrock manifesta-se no seguinte sentido:

\footnotetext{
Quando solicitados a se descreverem, os adolescentes têm mais probabilidade do que as crianças de usar termos abstratos e idealistas. Considere a descrição abstrata que Laurie, 14 anos, faz de si mesma: "Sou um ser humano. Sou indecisa. Não sei quem eu sou". Considere também sua descrição idealista de si: "Sou uma pessoa naturalmente sensível que realmente se preocupa com os sentimentos das pessoas." (SANTROCK, 2014, p. 154)
}

Ou seja, os jovens têm tendência, sobretudo adolescentes, em se enxergarem de forma idealizada, para além do que é real. Podem estar inclusive em busca de grandes causas para abraçarem.

Por isso, esta é fase da vida que a pessoa está mais sujeito a sofrer influencias ambientais, inclusive de docentes, também por possuírem pouco discernimento, quanto experiência para fazer escolhas seguras.

Portanto, deve-se observar o princípio da prevalência dos interesses das crianças e dos adolescentes, como critério interpretativo das demais normais legais, com absoluta prioridade.

\section{COLISÃO ENTRE O DIREITO DE ENSINAR LIVREMENTE E A PREVALÊNCIA DOS INTERESSES DA CRIANÇA E DO ADOLESCENTE}

Inicialmente, importante se faz ressaltar que os princípios não são aplicáveis, pelo sistema tudo ou nada, devendo haver ponderação e aplicação parcial, para que nenhum destes seja excluído do sistema. Tratando da colisão entre os princípios constitucionais e sua ponderação, manifesta-se Alves, no seguinte sentido:

Diferentemente do que ocorre entre as regras os princípios não são incompatíveis entre si, mas concorrentes. No caso de princípios, o conflito pode existir em nível fático, e em existindo, não há necessidade de uma das normas-princípio ser eliminada do 
sistema. O conflito, quando manifestado, não conduz a uma antinomia jurídica (ALVES, 2011, s/p).

No mesmo sentido, deve-se observar que no caso de conflito ou concorrência entre princípios constitucionais, não deve haver sacrifício total de um deles, deve-se buscar sempre a compatibilização, pois não existe hierarquia entre eles (VASCONCELOS, 2017).

Tampouco, qualquer princípio pode ser considerado absoluto, ainda que se tratando de direitos e garantias fundamentais, encontram limites por outros direitos igualmente previstos na constituição (VASCONCELOS, 2017).

Quanto à ponderação Bessa (2005) afirma que são três as suas fases, sendo a primeiro a identificação das normais fundamentais em conflito; a segunda é examinar a repercussão fática, assim como sua repercussão; e, por fim, deve haver uma apreciação conjunta dos diferentes grupos de normas e a repercussão dos fatos sobre eles, se atribuindo pesos aos diferentes elementos de colisão, se determinado quais devem prevalecer e em que intensidade sobre os demais.

Para Barcellos a interpretação do texto normativo estará sempre inserido em um campo mais amplo, o qual deverá ser levado em consideração pelo interprete, in verbis:

\footnotetext{
A interpretação constitucional parte, como a interpretação de qualquer norma jurídica e, a rigor, de qualquer texto, do elemento semântico: isto é, do texto e suas possibilidades de sentido. Em segundo lugar, o texto normativo específico estará sempre inserido em um contexto mais amplo, que precisará necessariamente ser considerado: trata-se do elemento sistemático de interpretação. (BARCELLOS, 2018, p. 70)
}

Já com relação ao problema apresentado neste estudo, o conflito está entre a liberdade de cátedra do docente para ensinar (amparado como direito fundamental no artigo $5^{\circ}$ da Constituição Federal como liberdade de manifestação do pensamento, liberdade de expressão da atividade intelectual e liberdade de profissão) em contra ponto ao o princípio da prevalência dos interesses da criança e adolescente (igualmente amparado no Art. 227 da mesma Constituição Federal).

Pois bem, nesse quadro, até que ponto o docente que leciona para crianças ou adolescentes é livre para externar suas opiniões pessoais?

Os adolescentes estão em uma fase de vida onde não estão com pleno desenvolvimento cognitivo, tendo propensão para atitudes exageradas e de risco. Também querem se firmar como indivíduos autônomos, se diferenciar, e criar sua própria identidade (SANTROCK, 2014) 
$\mathrm{Na}$ tentativa de criar sua própria identidade e se enxergar como alguém no mundo, o jovem pode replicar modelos de pessoas que admira, porque são o que o jovem pretende se parecer. (SANTROCK, 2014)

Neste quadro, não parece ser difícil que um docente, que exerce a função de liderança como adulto no comando, tenha suas opiniões e ideias replicadas por discentes, sobretudo adolescentes, ainda mais se for um docente com "atitude" com ideais e tentativas de rompimento com o establishment.

Travincas afirma que ensinar é um direito que compreende exigências, estando firmado em termos contratuais, acaba se convertendo em um verdadeiro direito-dever, pois uma vez contratado, deve ser cumprido o ajuste, in verbis:

[...] aquele a quem compete ensinar, cuja atividade é previamente firmada em termos contratuais, não pode optar não fazê-lo. Da mesma forma, não comporta se falar em um direito à liberdade de ensinar previamente à firmação do contrato de prestação de serviço. Ou seja, não há direito de ser contratado para ensinar, à revelia de prérequisitos. Disso se extrai que a liberdade de ensinar é um direito cujo exercício precede o cumprimento de exigências, além do que, revestindo-se dele, o titular não tem o direito de não exercê-lo, o que lhe confere uma feição de direito-dever (TRAVINCAS, 2016, p. 119)

Continuando em sua linha de raciocínio, Travincas afirma que não se pode considerar iguais condutas o uso da liberdade de expressão em locais públicos, de utilizar a mesma liberdade em sala de aula, onde deve haver manifestação de acordo com as competência exigidas da área de conhecimento lecionada, in verbis:

\footnotetext{
observe-se que a faculdade de manifestação, em um espaço público, no uso da liberdade de expressão, em muito se distancia do dever de se manifestar de acordo com as competências exigidas em uma área do conhecimento, daí o fundamento de a liberdade de ensinar não abarcar a conduta de ensinar sem bases técnicas (TRAVINCAS, 2016, p.120)
}

Logo, um docente que leciona para adolescente, não deve externar suas opiniões pessoais sobre política, religião e outros temas sensíveis, restringindo-se em cumprir os objetivos fixados para a disciplina.

Uma vez que ao contrário do que ocorre com discentes adultos, já na Universidade, estes não têm o discernimento completo para apurar o que é certo ou errado, tornando-se presas fáceis das mais diferentes ideologias não relacionadas com a matéria.

Quanto ao assunto, Rodrigues e Marocco, assim manifestam-se: 


\begin{abstract}
A liberdade de cátedra existe como instrumento do direito à educação - é uma liberdade meio -, o que implica que deve ser garantida para permitir que se alcance os objetivos fixados. Se ela surgir como um entrave é porque está sendo desvirtuada. A liberdade de ensinar, antes de se configurar em um direito individual do docente a liberdade de cátedra - configura-se como uma liberdade 15 compartilhada por todos os docentes e partilha espaço com o direito de aprender compartilhado por todos os discentes. (RODRIGUES \& MAROCCO, 2014, p.14-15)
\end{abstract}

Logo, o foco do docente em sala de aula deve ser nos objetivos traçados. O direito do discente, neste caso específico, acaba se sobrepondo ao dos docentes.

Portanto, na colisão de direitos, devem prevalecer, os interesses do discente adolescente, em detrimento a liberdade de cátedra do docente, a qual encontra limites nos interesses dos menores que estão durante o momento da aula, sob a responsabilidade do profissional de educação. Não tendo esta liberdade plena para expor o que bem entender, devendo observar as diretrizes previamente fixadas.

\title{
4 CONCLUSÃO
}

Com relação à liberdade de cátedra foi constatado que esta tem previsão constitucional, bem como, que isto pode ser decorrente do momento histórico em que a Norma Ápice foi votada, uma vez que o país havia recém saído de um período ditatorial e de forma repressão as liberdades.

Além de estar previsto no texto constitucional, o Supremo Tribunal Federal vem assegurando a liberdade de cátedra em sentido amplo, dando interpretação "elástica" ao texto em favor de maiores liberdades em sala de aula pelos docentes.

Foi dissertado sobre o Princípio da Prevalência dos Interesses da Criança e do Adolescente, com foco no fato deste decorrer do próprio texto constitucional que estabelece absoluta prioridade para os interesses das crianças e dos adolescentes.

Também foram apresentadas as justificativas para os tratamentos diferenciados dos adolescentes do ponto de vista biológico, uma vez que estes não tem o completo desenvolvimento cognitivo, estando mais receptivos para comportamentos de risco.

Os adolescentes também estão em busca de um ideal, que ajude a justificar quem são e qual o seu lugar no mundo, sendo em razão disso, extremamente influenciáveis, sobretudo por coisas que os diferenciem, ou seja, por discursos e ideias contrárias ao establishment.

No terceiro tópico do artigo foram analisados quais as saídas quando há um conflito entre princípios constitucionais. Onde foi constatado que se deve primeiro encontrar o conflito, 
depois contextualizá-lo com todo o entorno (tempo, lugar e demais particularidade) do caso em concreto, para depois decidir qual princípio deve prevalecer.

No caso em análise, o conflito está entre a liberdade de cátedra do docente e a liberdades desta decorrente, em contraponto com o Princípio da Prevalência dos Interesses da Criança e do Adolescente.

Pois bem, após todo o explanado, constata-se que o direito do segundo deve prevalecer, sem que os direitos do docente sejam limitados por completo, uma vez que possuem o direito de livre ensinar.

Neste sentido, o docente tem liberdade de escolher o método didático, pode expor o conteúdo programático previsto com todas a suas nuances e pormenores, mas deve se abster de trazer suas opiniões pessoais sobre temas não relativos a aula, sobretudo convicções políticas, religiosas, de sexualidade e com juízos valorativos.

Ou seja, os discentes não podem tornar-se público para atividades políticas e de ativismo ideológico, uma vez que os adolescentes não tem o pleno desenvolvimento mental, para discernir sobre a pertinência ou não das convicções pessoais do docente.

Portanto, conclui-se que há limites para a cátedra de docente que leciona para adolescentes, que se encontra no Princípio da Prevalência dos Interesses da Criança e do Adolescente. Logo, o adolescente deve de ter acesso ao conhecimento previsto para sua idade e série, sem sofrer doutrinações políticas e ideológicas, frutos de uma opinião pessoal do docente.

\section{REFERÊNCIAS}

ABRÃO, Bernardina F.F. Da Educação. In. MACHADO, Costa (Org.); FERRAZ, Anna Cadida da Cunha (coord.). Constituição Federal: Artigo por Artigo, Parágrafo por Parágrafo. 7 ed. Barueri, SP: Manole, 2016.

ARAÚJO JÚNIOR, Gediel Claudino de. Prática no Estatuto da Criança e do Adolescente. 3. ed. São Paulo: Atlas, 2019.

BARCELlOS, Ana Paula de. Curso de Direito Constitucional. Rio de janeiro: Forense. 2018.

ALVES, André Luis Dornellas. Colisão e Ponderação entre Princípios Constitucionais. Disponível em: http://www.egov.ufsc.br/portal/ conteudo /colis\%C3\%A3o-epondera\%C3\%A7\%C3\%A3o-entre-princ\%C3\%ADpios-constitucionais. Acesso em: 15 jan. 2020.

BESSA, Leandro Souza. Colisão de direitos Fundamentais: Propostas de Solução. 2005. Disponível em: http://www.publicadireito.com.br/conpedi /manaus/ arquivos/ anais/XIVCongresso/125.pdf. Acesso em: 15 jan. 2020. 
BRASIL. Constituição da República Federativa do Brasil (1988). Disponível em: http://www.planalto.gov.br/ccivil_03/Constituicao/Constituicao.htm. Acesso em: 01 jan. 2020.

BRASIL. Lei $\mathbf{n}^{\circ} 8.069$ de 13 de julho de 1990. Estatuto da Criança e do Adolescente. Disponível em: http://www.planalto.gov.br/ccivil 03/ leis/ 18069 .htm. Acesso em 14 jan. 2020.

CARBONELL, Jaume. Pedagogias do Século XXI: bases para a inovação educadora. 3. Ed. Porto Alegre: Penso, 2016.

ELIAS, Roberto João. Comentários ao Estatuto da Criança e do Adolescente. 4. ed. São Paulo: Saraiva, 2010.

LANDO, Giorge Andre; CUNHA, Sabrina Gislana Costa da; SOUZA LIMA, Maria Madalena de. A FUNÇÃO SOCIAL DA FAMílla NA PROMOÇÃO DO DIREITO À EDUCAÇÃO. Revista Juridica, [S.1.], v. 2, n. 43, p. 622 - 655, fev. 2017. ISSN 2316-753X. Disponível em: <http://revista.unicuritiba.edu.br/index.php/RevJur/article/view/1860/1231>. Acesso em: 21 abr. 2020. doi:http://dx.doi.org/10.21902/revistajur.2316-753X.v2i43.1860.

MAAS, Gilberto Natal; CANABARRO, Ivo dos Santos. Os Adolescentes: (DES) Construções do Sujeito Através da Imagem. Disponível em: file://C:/Users/Usu\%C3\%A1rio/Downloads/11783-3968-1-PB.pdf, Acesso em: 14 jan. 2020.

MICHAELIS. Dicionário. Disponível em: http://michaelis.uol.com.br/ busca? $\mathrm{r}=0 \& \mathrm{f}=0 \& \mathrm{t}=0 \&$ palavra=catedra. Acesso em 13 jan. 2020.

RODRIGUES, Horácio Wanderlei; MAROCCO; Andréa de Almeida Leite. Liberdade de cátedra e a Constituição Federal de 1988: Alcance e Limites da Autonomia Docente. Disponível em: https://abmes.org.br/ arquivos/documentos/hwr_artigo2014liberdadecatedra_unifor.pdf. Acesso em: 14 jan. 2020.

ROSSATO, Luciano Alves; LÉPORE, Paulo Eduardo; CUNHA, Rogério Sanches. Estatuto da Criança e do Adolescente: Comentado Artigo por Artigo. 9. ed. São Paulo: Saraiva, 2017.

SANTROCK, John W. Adolescência. 14. ed. Porto Alegre: AMGH, 2014.

STF. ADPF 548. Relatora: Ministra Carmem Lúcia. Disponível em: https://portal.stf.jus.br/processos/detalhe.asp?incidente=5576416. Acesso em: 13 jan. 2020.

TAVARES, André Ramos. Curso de Direito Constitucional. 16.ed. São Paulo: Saraiva, 2018.

TELLES JUNIOR, Goffredo. Carta aos Brasileiros 1977. 2. ed. São Paulo: Saraiva, 2016.

TRAVINCAS, Amanda Costa Thomé. A Tutela Jurídica da Liberdade Acadêmica no Brasil: A Liberdade de Ensinar e Seus Limites. Tese (Doutorado em Direito) - Pontifícia Universidade Católica do Rio Grande do Sul - PUCRS. Porto Alegre, 2016.

VASCONCELOS, Cleber. Curso de Direito Constitucional. 4 ed. São Paulo: Saraiva, 2017. 